\title{
Construções condicionais insubordinadas adversativas no português brasileiro
}

DOI: http://dx.doi.org/10.21165/el.v50i2.2986

\section{Camila Pires Alves ${ }^{1}$ \\ Flávia Bezerra de Menezes Hirata-Vale²}

\section{Resumo}

Considerando a emergência de estudos sobre o fenômeno da "insubordinação" (EVANS, 2007), este trabalho tem por finalidade descrever os usos de construções condicionais insubordinadas $(\mathrm{CCl})$ encabeçadas por "se" com valor adversativo no português do Brasil, ainda não plenamente descritos nesta língua. Para tal, foi utilizada a abordagem funcionalista (NEVES, 2000, 2002) e a perspectiva teórica de autores como Sansiñena (2015), Schwenter (2016) e Montolío (1999). Os dados foram coletados em corpora de língua falada (Corpus do Português e Corpus C-Oral-Brasil) e analisados qualitativamente. Em termos formais, nessas construções emprega-se o do modo indicativo, motivado por seu estatuto factual. As CCls adversativas são utilizadas em posição de réplica, por ocorrerem em contextos dialógicos. Pragmaticamente, são caracterizadas por apresentar um caráter de rispidez, decorrente da relação simétrica entre os interlocutores.

Palavras-chave: insubordinação; condicionalidade; adversatividade; contrastividade; funcionalismo.

\footnotetext{
1 Universidade Federal de São Carlos (UFSCar), São Carlos, São Paulo, Brasil; camilacup@live.com; https://orcid.org/0000-0001-7513-1118

2 Universidade Federal de São Carlos (UFSCar), São Carlos, São Paulo, Brasil; flaviahiratavale@ufscar.br; https://orcid.org/0000-0002-9091-9461
} 


\title{
Adversative insubordinate conditional constructions in Brazilian Portuguese
}

\begin{abstract}
Considering the emergence of studies on the phenomenon of "insubordination" (EVANS, 2007), this work aims to describe the uses of insubordinate conditional constructions (ICCS) headed by "if" with an adversative value in Brazilian Portuguese, as it has not been yet fully described in this language. For this, the functionalist approach (NEVES, 2000, 2002) and the theoretical perspective of authors such as Sansiñena (2015), Schwenter (2016), and Montolío (1999) were used. The data were collected in spoken language corpora (Corpus do Português and Corpus C-Oral-Brasil) and analyzed qualitatively. In formal terms, these constructions are used in the indicative mood, motivated by their factual status. Adversative CCls are used in a replica position, as they occur in dialogical contexts. Pragmatically, they are characterized by a harsh character, which may be due to the symmetrical relationship between the interlocutors.
\end{abstract}

Keywords: insubordination; conditionality; adversativity; contrastiveness; functionalism.

\section{Apresentação}

No processo de construção de um período, há dois tipos de operações principais que são mobilizadas e articuladas. De acordo com a gramática normativa, essas operações são realizadas por meio de orações complexas denominadas "subordinadas" e "coordenadas".

A subordinação ou hipotaxe ocorre, partindo das definições de Evanildo Bechara (2009), também compartilhada em/por gramáticas/gramáticos, quando uma oração se encontra em estado de pertença (subordinada), fazendo com que ela seja um membro sintático de uma outra unidade (oração). Um dos critérios para estabelecer se uma oração é subordinada ou não é o uso de conjunções (ou locução conjuntiva) subordinativas, como as conjunções integrantes (como o "que" e o "se"), adverbiais ("se", "que", "porque", "visto que"), etc.

As construções complexas tratadas aqui, há algum tempo, têm sido uma questão central em trabalhos de perspectiva funcionalista. Matthiessen e Thompson (1988), dentre outros pioneiros, estabeleceram seu estatuto como um fenômeno discursivo a partir de considerações que viam o processo de combinação de orações não somente do ponto de vista gramatical, mas também, com a inclusão do ponto de vista discursivo.

Ademais, essa nova perspectiva de olhar para as construções complexas implicou uma revisão do modelo tradicional referente à distinção entre os processos de subordinação 
e coordenação de orações. Isso ocorreu porque as separações dicotômicas propostas pelos modelos gramaticais mostram-se insuficientes para uma série de fenômenos linguísticos, e, assim, passaram a ser analisadas considerando o real uso linguístico, em situações efetivas.

Consequentemente, algumas propostas de classificação foram formuladas por Halliday (1985), Lehmann (1988), Hopper e Traugott (2003), Verstraete (2007), entre outros, com a finalidade de superar as limitações que a abordagem gramatical estabelece. Especificamente no caso do português do Brasil (doravante "PB"), destacam-se trabalhos realizados por Decat (1993) acerca de análises de hipotaxe adverbial nessa língua, a partir de uma perspectiva discursivo-funcionalista.

Recentemente, há muitos estudos debruçados em um fenômeno linguístico referente ao uso não-prototípico das construções complexas, isto é, casos de construções que, ainda apresentando alguma marca de subordinação, são utilizadas de forma independente, sem estarem relacionadas a uma oração principal, como é perceptível no exemplo:

1. If you could just sit here for a while please. (EVANS, 2009, p. 1).

Se você puder sentar aqui por um momento por favor.

Esse processo é chamado de "insubordinação", termo cunhado por Evans (2007), em um de seus trabalhos a partir de uma concepção tipológica, e é entendido, desde então, como "o uso convencionalizado como orações principais, de orações que, à primeira vista, parecem formalmente ser orações subordinadas" (EVANS, 2007, p. 367, tradução nossa $\left.{ }^{3}\right)$.

Em decorrência disso, há muitos trabalhos realizados e ainda em desenvolvimento a respeito deste tema sob responsabilidade de diferentes autores, não somente Evans. Esses trabalhos apresentam tanto um olhar tipológico como também um olhar voltado para a descrição de uma língua especificamente (EVANS, 2007; MITHUN, 2008; VAN LINDEN; VAN DE VELDE, 2014; HIRATA-VALE, 2015, 2017; MONTOLÍO, 1999; SANSIÑENA, 2015; SCHWENTER, 1999, 2016).

Evans (2007), ao descrever a insubordinação, propõe um modelo de desenvolvimento desse fenômeno que parte da elipse da oração principal e percorre etapas seguintes até que se atinja um uso independente. Tal processo, segundo o autor, ocorre em quatro fases:

3 No original: "The conventionalized main clause use of what, on prima facie grounds, appear to be formally subordinate clauses". 
Quadro 1. Quadro de estágios de insubordinação

\begin{tabular}{|c|c|c|c|}
\hline Subordinação & Elipse & $\begin{array}{c}\text { Elipse } \\
\text { Convencionalizada }\end{array}$ & $\begin{array}{c}\text { Re-análise como } \\
\text { oração principal }\end{array}$ \\
\hline$(1)$ & $(2)$ & $(3)$ & $(4)$ \\
\hline Oração subordinada & $\begin{array}{c}\text { Elipse da oração } \\
\text { principal }\end{array}$ & $\begin{array}{c}\text { Restrição à } \\
\text { interpretação do } \\
\text { material elíptico } \\
\text { como principal }\end{array}$ & $\begin{array}{c}\text { Uso convencionalizado } \\
\text { de oração originalmente } \\
\text { subordinada } \\
\text { (Construcionalização) }\end{array}$ \\
\hline
\end{tabular}

Fonte: Evans (2007, p. 370)

Evans (2007) elenca três grandes funções da insubordinação e as define como: (I) Controle interpessoal (para expressão de pedidos, ameaças, instruções, ou seja, imperativos); (II) Modalização (epistêmica, evidencial, deôntica e por construções exclamativas ou avaliativas; (III) Sinalização de material pressuposto (a negação, o foco contrastivo, referências cruzadas, afirmações precedentes na interação, entre outros).

Outro autor pioneiro na descrição das construções insubordinadas é Schwenter (1999, 2016). O autor analisa especificamente as construções condicionais insubordinadas (CCls) e argumenta que, ainda que as construções condicionais exprimam uma ideia semântica de uma hipótese ou algo irreal, elas podem ser utilizadas como construções independentes e podem exprimir uma ideia de algo factual e real. Para ele, o significado hipotético atribuído ao "se" deve ser analisado como um caso de "implicatura conversacional griceniana" ou "GCl", ao invés de ser analisado a partir do aspecto codificado do significado dessa conjunção. Para o filósofo Grice (1990 apud SCHWENTER, 1999) e outros pragmaticistas, as "GCls" são inferências padronizadas que são transmitidas pelas formas que as carregam e relacionam-se a formas linguísticas particulares, porém, reversíveis.

As orações independentes, segundo Schwenter (1999), representam uma construção particular que ocorreu com uma frequência suficiente em um dado contexto em que a GCl foi bloqueada, permitindo assim uma convencionalização de um significado não condicional, qual seja, o adversativo. Portanto, os marcadores condicionais não se limitam a contextos prototípicos hipotéticos/irreais como as gramáticas normativas tratam, pois eles demonstram estar relacionados ao discurso natural (o uso linguístico na prática real), como parte de algo compartilhado entre locutores em situações de fala.

Relativamente à discussão do fenômeno da insubordinação no português brasileiro, destacam-se as pesquisas realizadas por Hirata-Vale $(2015,2017)$. A partir da teoria funcionalista, a autora estabeleceu os contextos discursivos nos quais essas construções 
são usadas, bem como suas características formais e funcionais, concluindo que as CCls têm diferentes configurações estruturais, que vão desde as mais livres, ou instantâneas, até as mais rígidas, ou formulaicas, em consonância com a proposta de Heine, Kaltenbock e Kuteva. Hirata-Vale $(2015,2017)$ constata ainda que, ao longo do processo de insubordinação, as construções condicionais prototípicas (iniciadas com a conjunção "se") perdem gradativamente o seu valor semântico hipotético (condicional) e novos valores semânticos, como o adversativo, são determinados pragmaticamente. Por isso, não podem ser analisadas pelos parâmetros de condicionalidade de Dancygier (1998, apud HIRATA-VALE, 2015).

Em vista do exposto, o que se pretende com este trabalho é apresentar a análise e descrição dos aspectos morfossintáticos e semântico-pragmáticos das CCls com valor adversativo no português do Brasil, fenômeno este ainda não absolutamente descrito nessa língua. A análise está fundamentada em princípios funcionalistas (NEVES, 2000, 2002) e, portanto, os dados foram coletados e observados considerando seus contextos de uso e a função exercida por essas construções nesses contextos.

Para tanto, este trabalho está organizado da seguinte forma: após as considerações iniciais, apresentam-se os principais pressupostos teóricos que norteiam o trabalho, o que inclui o processo de insubordinação condicional e apresentação de alguns estudos das CCls adversativas em espanhol. Na seção seguinte, discutem-se a metodologia de análise, a formação do corpus e os critérios de análise. Na sequência, expõem-se a análise e a descrição das ocorrências das CCls adversativas no PB a partir de uma perspectiva funcional da linguagem. Por fım, apresentam-se as considerações finais.

\section{Fundamentação teórica}

No que diz respeito especialmente aos usos adversativos ${ }^{4}$ das construções condicionais insubordinadas, destacam-se os trabalhos de Montolío (1999) e Schwenter (1999, 2001, 2016) no espanhol.

No espanhol, como aponta Montolío (1999), o si condicional difere da natureza semânticopragmática do si adversativo. A autora constatou que, além da conjunção condicional si, a própria conjunção adversativa pero ("mas", em português) também pode integrar uma $\mathrm{CCl}$ com valor adversativo, como no exemplo a seguir:

4 É importante destacar que o termo "adversativo" é empregado neste trabalho no sentido de oposição/contraste, tal como é, de modo geral, atribuído às conjunções adversativas. Isto é, a conjunção "se" perde seu traço condicional e expressa, dentre outras características a serem apresentadas neste artigo, um sentido de contraste ao que foi dito anteriormente. 
2. ¿QQué tal? ¿Cómo te va tu coche nuevo?

-Pero si me compré una moto. (MONTOLío, 1999, p. 40).

-Como vai? Como vai o seu carro novo?

-Mas se eu comprei uma moto.

Casos como este, segundo Montolío (1999), são muito frequentes no espanhol falado e, apesar de essas duas conjunções apresentarem funções diferentes (adversatividade e condicionalidade, respectivamente), ao serem usadas em conjunto, compõem uma estrutura que exerce o papel de intensificador da contra-argumentação ríspida e de oposição ao que foi dito anteriormente.

Nesse sentido, Montolío (1999) defende a tese de que as CCls com valor adversativo passaram pelo processo de gramaticalização de sua forma originalmente condicional e atingiram seu grau de autonomia ao expressarem a adversatividade. Como um argumento para a sustentação dessa proposta, a autora relata ser perceptível o fato de que o "si" perde sua transparência semântica e codifica outros valores característicos da função discursiva de réplica, uma vez que assume distintas funções semânticas.

Ao identificar um processo de gramaticalização em alguma estrutura linguística, consequentemente, se identificam mudanças de ordem morfossintática. No caso das CCls adversativas, em oposição às condicionais canônicas, não é possível a flexão para o subjuntivo e nem a coordenação de orações. É possível somente a justaposição das orações, como pode ser observado nos exemplos seguintes:

3. - ¿Qué tal? ¿Cómo te va tu coche nuevo?

(a) - Pero si me compré una moto

(b) - Pero si me comprara una moto* (MONTOLíO, 1999, p. 40).

4. - ¿Vendrás a la reunión de mañana?

(a) - Si he acabado la traducción y si puedo encontrar a alguien que me sustituya en la clase, sí que iré;

(b) -(Pero) si no es mañana y si no estoy convocada.* (MONTOLío, 1999, p. 41).

No exemplo (3), o modo subjuntivo torna a sentença agramatical, pois essas construções não são utilizadas para expressar hipoteticidade, mas sim factualidade. No exemplo (4), a estrutura de (b) está correta gramaticalmente, porém revela-se inadequada em relação a sua pragmática. 
Nessas construções, o falante também expressa que considera incoerente o enunciado antecedente, que pode apresentar um caráter de obviedade, como se vê no próximo exemplo:

$$
\begin{aligned}
& \text { 5. - Pásame el pastel, por favor } \\
& \text { - Si estás a régimen... (MONTOLíO, 1999, p. 59) }
\end{aligned}
$$

Em alguma medida, esse enunciado precedente não é condizente com o conhecimento prévio de quem o contesta, fato que traz à tona a necessidade da colocação de um commom ground na interação. Nesse caso, a CCI indica que o falante considera incoerente seu interlocutor pedir um doce, já que está de regime, informação que ambos compartilham em seu contexto.

Schwenter, também no final da década de 1990, analisou, especificamente, as construções condicionais com valor adversativo no espanhol, como no exemplo seguinte:

6. [A is trying to get her children to put on a video for her]

A: Venga, ponerme "Sonrisas y Lágrimas."

U: Che, mamá, ¡si eso es un rollo!

A: Pues tú vas ahí dentro y no lo ves.

(SCHWENTER, 1999, p. 178).

[A está tentando fazer com que seus filhos gravem um vídeo para ela]

A: Vamos, coloque [a música] "Sonrisas y Lágrimas"

U: Nossa, mãe! Se isso é tão chato!

Para o autor, percebe-se que o falante $U$, em uma resposta a um pedido da mãe, utiliza uma oração condicional encabeçada pelo "se", que expressa um valor adversativo, de contrariedade, que se acrescenta ao condicional. O autor defende que os usos dessas condicionais insubordinadas diferem muito dos casos em que a condicional está associada a uma oração núcleo, sobretudo porque sua maior prevalência se dá em contextos dialógicos. Assim, segundo Schwenter (2013, p. 12, tradução nossa5), em trabalho mais recente,

5 No original: "[...] the function and syntactic placement of si differs greatly between its use in conditional sentences and its use in independent si- clauses. In the former, si is found on the syntactic level marking the relationship between adjacent clauses and providing information as to how to interpret the proposition in its scope with respect to the proposition derivable from its companion clause. By contrast, si in independent clauses marks a discourse- level relationship between adjacent utterances, typically [...] as produced by different speakers in a dialogual context. It seems clear that the connection between the subordinate clause use and the insubordinated, main clause use is mediated by dialogual context [...].". 
[...] a função e a colocação semântica do "se" em seus usos em orações condicionais e em orações "se-independentes" são bastante diferentes. No primeiro caso, "se" pode ser encontrado no nível sintático, marcando a relação entre orações adjacentes e fornecendo informações de como interpretar a proposição em seu escopo, com relação à proposição derivada da oração que acompanha. Por outro lado, "se" em orações independentes marca uma relação entre enunciados adjacentes em nível discursivo, tipicamente [...] como os produzidos por diferentes falantes no contexto do diálogo. Parece claro que a conexão entre o uso como oração subordinada e o uso insubordinado como oração principal é mediado pelo contexto dialógico [...].

Voltando ao tema nos anos seguintes, Schwenter (2016) descreveu as características formais e funcionais das CCls adversativas e as classificou como independentes, intersubjetivas e de refutação ("si-oração independente" ou "si-oração de refutação"). Essas orações são encontradas com frequência na fala, em contextos de refutação ou objeção imediatas ao que o interlocutor acaba de dizer, como no exemplo abaixo:

7. A: Los primos van a llegar esta tarde.

B: ¡Si ya han llegado esta mañana. (SCHWENTER, 2016, p. 2).

A: Os primos vão chegar esta tarde.

B: Se já chegaram esta manhã!

Na oração (A), observa-se um ato de fala no qual algo é afirmado. Já na oração (B), verifica-se que o marcador "si", embora seja um marcador típico de orações condicionais em espanhol, é utilizado nesse contexto para contradizer o que foi dito anteriormente pelo interlocutor (A), com o objetivo de demonstrar uma refutação sobre a declaração. Dessa forma, segundo o autor, se o "si" fosse removido da oração, não haveria perdas em termos de conteúdo: "¡Ya han llegado esta mañana!" "Já chegaram esta manhã"). No entanto, em termos pragmáticos, haveria uma perda crucial, pois o caráter de refutação desapareceria e, por conseguinte, a relação entre as falas de (A) e (B) seria menos óbvia (SCHWENTER, 2016).

Realizando testes contrastivos entre as condicionais subordinadas prototípicas e condicionais insubordinadas, Schwenter (2016) concluiu que o conectivo "si", nos casos de construções subordinadas, requer o uso de modos e tempos verbais específicos, sendo estes subjuntivo ou passado imperfeito. Nos casos de construções insubordinadas, a depender do sentido pragmático, o "si" requer verbos conjugados necessariamente no modo indicativo, por exemplo, nas CCls adversativas. A utilização do modo indicativo contribui para a compreensão semântico-pragmática dessas construções. 
Para o português brasileiro, esses usos foram brevemente tratados por Hirata-Vale (2015), como se vê no exemplo abaixo:

8. - Depois; agora vamos à fazenda.

- Eu não! disse Miguel prontamente.

- Que pirraça é esta?

- Não tenho que fazer lá.

- Mas tenho eu.

- Todos os dias? - Perguntou Miguel fitando nela um olhar perscrutador.

- Se eu gosto! (CdP).

A autora considera que essa ocorrência demonstra que a construção condicional insubordinada desempenha um papel na interação entre falante e ouvinte. Sendo assim, essas construções podem ser consideradas como intersubjetivas, posto que possibilitam ao falante a oportunidade de expressar que está consciente das atitudes e crenças do ouvinte especificamente no que se refere à sua imagem ou face por meio da expressão de um valor de contraste, que poderia ser parafraseado por "mas eu gosto".

A partir das considerações apresentadas, verifica-se que o fenômeno da insubordinação condicional com valor adversativo no português brasileiro ainda é pouco descrito, o que justifica a realização deste trabalho. Na sequência, apresentam-se os procedimentos metodológicos utilizados na análise das ocorrências.

\section{Metodologia de análise}

Este trabalho tem por objetivo analisar e descrever os aspectos morfossintáticos e semântico-pragmáticos das CCls com valor adversativo no PB a partir de uma abordagem funcionalista (NEVES, 2000, 2002), classificando tais construções em termos formais e funcionais. Pretende-se, com este trabalho, contribuir para o melhor entendimento das construções insubordinadas e das construções condicionais no português de modo geral.

Para a composição do corpus, foram analisados e coletados dados do português do Brasil encontrados em dois corpora de língua falada e escrita, o Corpus do Português (CdP) e o Corpus C-Oral-Brasil (C-Oral) ${ }^{6}$.

6 Também foi realizada uma busca no corpus do Projeto Norma Linguística Urbana Culta - RJ (NURC), porém, não foram encontradas ocorrências de CCl adversativa. Inferimos que o insucesso de busca nesse corpus decorre do fato de que os dados não têm um caráter dialógico informal e natural. Sendo o objeto de análise desta pesquisa um fenômeno marcado pela oralidade e informalidade, é esperado que, em um corpus marcado pela polidez e formalidade nos dados, exista dificuldades para encontrar as CCls adversativas em virtude de seu contexto e caráter específico. 
Em relação ao Corpus do Português (CdP), tem-se um banco de dados muito extenso e rico, que permite as buscas dos dados a partir de comandos específicos. Diante desta possibilidade, as buscas de ocorrências nesse corpus foram realizadas na versão Gênero/ Histórico, utilizando o método de busca parts of speech, [POS]. Com ele, é possível realizar combinações lexicais que iniciam o comando de busca com outras classes gramaticais, pontuação ou tempos/modos verbais específicos. Além disso, por meio do símbolo * (asterisco), é possível realizar buscas por sentenças em que o espaço preenchido por este símbolo possa ser ocupado por alguma palavra ou pontuação, sem uma especificidade.

O C-Oral-Brasil oferece dados a partir de amostras de áudio e de transcrições diretas de falas espontâneas do português brasileiro. Por isso, essas transcrições apresentam muitas gírias e marcas de oralidade, típicas de contextos informais. Como as construções aqui analisadas são encontradas em contextos dialógicos informais, o C-Oral-Brasil forneceu dados que demonstram a emergência das CCls adversativas em falas efetivamente espontâneas e diretas na modalidade falada (amostras de áudio) e escrita (por transcrição de cada amostra).

Toda a busca foi realizada de modo manual, analisando isoladamente cada dado dos corpora e atestando, a partir da leitura dos textos teóricos referentes à categorização das CCls com valor adversativo, se os resultados das buscas correspondiam a esse tipo de estrutura para que fossem incluídos no conjunto de exemplares a serem analisados.

Com a elaboração de um corpus qualitativo, foram observados os traços morfossintáticos, sintáticos, semânticos e pragmáticos dessas construções. Dessa forma, pautado na regularidade desses traços, descreveu-se a forma e a função das CCIs adversativas. Para isso, tal como propõe a corrente epistemológica funcionalista que norteia este trabalho, foram considerados e examinados os contextos de emergência dessas construções para o estabelecimento de seus aspectos formais e funcionais.

\section{Análise dos dados}

A CCI adversativa ora estudada tem como composição básica uma oração encabeçada pela conjunção "se" independente, isto é, não subordinada a uma oração anterior/ principal. Portanto, do ponto de vista formal, a utilização da conjunção "se" é um aspecto fundamental e elementar nessas construções, como nos seguintes exemplos:

9. - E ele quer-me, depois de eu me ter negado? - Disse o tenente Gonçalo Pereira.

- Se ele está apaixonado, filha... (CdoP/PB).

10. - Minha senhora, venho implorar a Vossa Excelência a honra de uma contradança.

- Mas se eu já tenho par para todas... (CdoP/PB). 
11. - No mais [...] pode tratar de vida nova! Nada o prende aqui. Estamos quites.

- Como? Se o senhor ainda não me fez as contas... (CdoP/PB).

Todas as ocorrências encontradas estavam no modo indicativo, ou seja, trata-se de uma característica essencial dessas construções, já que elas expressam um valor factual. Conforme identificou Hirata-Vale (2015), há algumas construções insubordinadas iniciadas com "se" que apresentam verbos conjugados no modo subjuntivo, porém, tais ocorrências não configuram uma CCI adversativa porque expressam um valor hipotético, não-factual. Nesse sentido, a análise confirma o que foi apontado por Montolío (1999, p. 41, tradução nossa ${ }^{7}$ ) para as condicionais adversativas do espanhol:

A retificação de uma premissa já declarada ou estabelecida constitui uma afirmação que não pode ser realizada por meio de uma expressão de virtualidade. Se poderia dizer, então, que esse esquema com si não compartilha da mesma natureza semântico-pragmática que o si condicional, uma vez que se afasta da noção de hipótese para se aproximar do modo de afırmação completa, para a expressão da factualidade dos feitos no mundo real.

O modo indicativo no português é composto por seis tempos verbais simples. Deles, cinco puderam ser atestados: presente, pretérito perfeito, pretérito imperfeito, pretérito mais-que-perfeito e futuro do presente. Não foram encontradas ocorrências com o futuro do pretérito (condicional) e depreende-se que isso se justifica pelo fato de que as CCls adversativas são incompatíveis com formas verbais que expressam hipótese. É o que se pode ver nos exemplos seguintes:

12. - Não faça isso - pediu Leninha, quase gritando, fazendo um esforço doido para não gritar - não faça isso que me machuca!

- Mas se eu quero machucar mesmo! Se é para machucar! (CdP/PB).

13. - Esta noite, quero levar você a uma parte.

- Eu não vou!

- Como há de ser agora? Se prometi a Senhora Romana. (CdP/PB).

7 No original: "La rectificación de una premisa ya enunciada o establecida constituye una aserción que no puede llevarse a cabo mediante una expresión de 'virtualidad'. Diríase, pues, que este esquema con si no comparte la misma naturaleza semántico-pragmática que el si condicional, ya que se aleja de la noción de hipótesis para acercarse al modo de la aserción plena, a la expresión de la factualidad de los hechos en el mundo real". 
14. - Pois saiba que foi ele, quem se atreveu a desfeitear-me.

- Deveras! O Carlito?! Aquele fedelho, aquele biltrezinho... Que atrevido, vou já puxar-lhe as orelhas e esfregá-lo a cachações.

- Arrancar-lhe o coração, e beber-lhe o sangue é o que eu queria... Mas escute, moço, eu preciso dizer-Ihe toda a verdade. Eu queria muito bem àquele menino..

- Queria-Ihe bem... deveras, Jupira... Ah, por que razão não me falou isso há mais tempo?

- Quirino soltou um gemido abafado.

- Como, se nem eu mesmo sabia? - replicou-lhe a moça. (CdP/PB).

15. "Todos se riam. Ela alargava os olhos, deslumbrada e triste. Mas era ouro! Se ela até ficara com medo de bulir! Estava tudo brilhando, lá embaixo. Não queriam acreditar! Pois ia buscar uns torrões". (CdP/PB).

16. - [...] E passada a adolescência não se pode mais recuperá-la. Com ela foram os nossos sonhos, as nossas experiências mais deliciosas, a liberdade de ser ou não ser.

- Você acha impossível recuperá-la?

- Acho.

- E se nós tentássemos?

- Como, se de hoje em diante só nos darão o direito de viver equilibrados? (CdP/PB).

Conclui-se, então, que qualquer tempo verbal que expresse uma ação ou acontecimento factual, tem seu uso admitido nas CCls adversativas, enquanto verbos que essencialmente denotem dúvidas ou hipóteses, como é o caso do futuro do pretérito ou verbos no modo subjuntivo, não são aceitos.

Além da especificidade quanto ao modo e aos tempos verbais, as CCls adversativas também permitem locuções verbais que anunciam o desenvolvimento gradual de uma ação. Essas locuções são formadas por um verbo auxiliar e um verbo principal em sua forma infinitiva ou no gerúndio. Essa junção determina com maior rigor o momento da ação verbal, ação esta que não se define na divisão geral e específica do presente, passado e do futuro (BECHARA, 2009). Abaixo, há um dado que exemplifica e demonstra tais características:

17. - E por que não se desfaz a senhora de semelhante bruto?! No fim de contas, deve ser aborrecido suportar eternamente este orangotango.

- Se lhe estou dizendo, senhor Duque, que o demônio do bicho tem faro! (CdP/PB). 
Alguns pronomes (como, para quê, quem, etc.) e a própria conjunção adversativa "mas" também fazem parte, como elementos acessórios e intensificadores, das CCls adversativas. Tal como explicitado anteriormente, esse tipo de construção ocorre em posição de réplica e expressa uma contra-argumentação, de modo rude e em desacordo ao que foi proposto anteriormente. Ao apresentarem esses pronomes ou a conjunção adversativa "mas", enfatiza-se a contestação e a falta de cortesia que as CCIs adversativas expressam. Além dos exemplos (14) e (16), as ocorrências seguintes também explicitam esse traço formal:

18. - Venha comigo... Assim nós conversamos enquanto eu me visto. Só que você vai ter que ficar de olhos fechados.

- Pra quê, se eu já vi? (CdP/PB).

19. - Agora, à segunda parte, meu arquiteto mirim, vamos construir sete abrigos, duas choças, três cabanas, um rancho e, por último, casa fortaleza.

- 0 quê? Se não sei o que um é outro. ( $C d P / P B)$.

No exemplo (18), constata-se, ainda, a retomada de um conteúdo elíptico, em que o "pra quê" substituiu o conteúdo "ficar de olhos fechados". Ainda, em casos similares, o pronome pode vir acompanhado de um advérbio de negação ou de afirmação para intensificar ainda mais a contestação em relação ao conteúdo elíptico:

20. - Ô seu Manuel de [...], sabe que o vapor sai as dez?

- Como não [saber]? Se ainda ontem à tarde lho mandei dizer... (CdP/PB).

Com relação à conjunção "mas" nas CCls adversativas, constatou-se que essa união resulta na intensificação do valor contrastivo sem modificar o valor proposicional da construção. No espanhol, o uso da conjunção adversativa "pero" com a conjunção condicional "si", ou seja, "pero si" é analisada por Montolío (1999) como um processo de gramaticalização. Por isso, não é possível introduzir nenhum constituinte oracional entre tais conjunções, salvo vocativos e interjeições. Por meio de testes dos dados analisados no PB, observou-se que essa mesma postulação feita por Montolío (1999) em espanhol aplica-se ao português. Os exemplos (21) e (22), além de exemplificarem usos de "mas se", mostram o uso de vocativos e interjeições:

21. Madame Vargas: - A cada passo penso que vão destruir a minha felicidade.

José: - Mas quem?

Madame Vargas: - Esta vida! Esta gente! 
José: - Mas se eu estou a seu lado? (CdP/PB).

_ Mas, [minha amada], se eu estou a seu lado?

_ Mas, [ó], se eu estou a seu lado?

22. -Não se conformava à insinuação de que Raul vivia Intimamente com Pedrina.

- Mas se ele me ama! (CdP/PB).

- Mas, menina, se ele me ama!

Outro aspecto muito importante definido por Montolío (1999) é a impossibilidade de coordenação das CCls adversativas em espanhol, sendo possível apenas a justaposição. Em PB, a mesma situação se verifica, como pode ser observado nos dados (12) e (23):

23. - Quantos sabiam do fato comentavam-no com acrimônia. Estava o João Duarte de dentro, com três virgens! Que sátiro! Sempre que a opinião da rua filtrava através das portas, a velha em cólera, bramia, gesticulava, bradava. E João, sem forças, dizia súplice:

- Mas se não é verdade? Se a senhora sabe que não tenho intensões más? (CdP/PB).

Quanto à organização dos turnos de fala e a localização das CCls adversativas, percebese que a posição mais regular é o início de turno. Porém, também é comum que ela seja precedida de outros turnos de fala, como, por exemplo, no dado (15). Da mesma forma, é possível que existam elementos na sequência da $\mathrm{CCl}$ adversativa, geralmente, para reiterar a contestação, como em:

24. - Mas não pense mais no Argemiro, mamãe...

- Hein! que idéia, não pense no Argemiro! Mas se ele é o marido que te convém! Julgas que é muito fácil encontrar um homem que reúna tantos predicados? (CdP/PB).

Em relação aos aspectos semânticos e pragmáticos, as CCls adversativas expressam rispidez e obviedade, diferentemente das construções condicionais prototípicas, que são, em muitos casos, usadas como estratégias de polidez. Consequentemente, as CCls adversativas são mobilizadas em situações de uma contra-argumentação ríspida, em que o falante expressa obviedade e indignação acerca da declaração de seu interlocutor.

Montolío (1999) afirma que as construções de réplica ou de contra-argumentação têm, naturalmente, funções discursivas que ameaçam as imagens sociais dos interlocutores. Logo, uma refutação pode ser formulada segundo princípios de cortesia linguística como um mecanismo de resguardo e discrição em contextos dialógicos, assinalando uma relação assimétrica entre os interlocutores. 
Portanto, quanto mais simétrica é a relação entre interlocutores, maior a possibilidade de emergência das CCls adversativas a partir da intenção de demonstrar obviedade sobre o que se fala sem a necessidade de polidez. Nesse sentido, esse tipo de estrutura é habitualmente utilizada em contextos dialógicos onde existe uma certa confiança entre os interlocutores, fazendo com que ambos possam corresponder-se mutuamente.

Embora a ausência do "se" não modifique o conteúdo proposicional da construção, os valores de contra-argumentação, obviedade, discordância e indignação por parte do falante são instaurados pragmaticamente com o uso dessa conjunção. É o que se pode notar na ocorrência seguinte, em que se testou a omissão do "se" para a verificação da mudança pragmática:

25. - É o mais certo! Dizem que estão lhe pondo o cerco.

- Ora, isso há muito tempo!

- Mas um dia chega a caipora.

- Como? Se ninguém sabe onde ele vive... (CdP/PB).

- Como? Ninguém sabe onde ele vive...

Assim como postula Schwenter (1999), conclui-se que no PB a conjunção "se" é a responsável por causar um efeito de contra-argumentação e rispidez nas CCls adversativas. Isso significa que a omissão da conjunção "se", como testado acima, anula suas características pragmáticas peculiares, inclusive nos casos em que as CCls adversativas são antecedidas por interjeições ou pronomes, como no mesmo exemplo anterior. Nesse último caso, a omissão da conjunção "se" explicita a causalidade entre a $\mathrm{CCl}$ adversativa e a refutação (implícita) que a precede:

26. - Quê! Pois ele lhe fez presente de todo o doce que recebeu do Norte?

- Ora! Se te estou a dizer! (CdP/PB)

- Ora! Te estou a dizer!

27. - Diga-me uma cousa, D. Firmina!

- O que é, Aurélia?

- Mas há de ser franca. Promete-me?

- Franca? Mais do que eu sou, menina? Se é este o meu defeito... (CdP/PB)

- Franca? Mais do que eu sou, menina? É este o meu defeito... 
A ausência da conjunção "se" faz com que o interlocutor infira a causalidade da construção, posto que a condição para a refutação não é evidente e o argumento que segue é configurado como uma nova informação. Por isso, salienta-se a importância da conjunção "se" nessas construções, conjunção esta responsável por inferir a um conteúdo preposicionado o caráter ríspido, de contradição, contra-argumentação, indignação e de obviedade em um contexto de réplica.

\section{Considerações finais}

Neste trabalho, descreveram-se os aspectos formais e funcionais das CCls adversativas no PB, que emergem em contextos dialógicos e que apresentam um caráter replicativo e ríspido.

Observou-se uma restrição no uso de verbos nessas construções, que precisam ser conjugados no modo indicativo. Considerando o caráter factual dessas construções, verbos no modo subjuntivo não são licenciados por expressarem essencialmente um valor hipotético, não condizente com as CCls adversativas.

Sintaticamente, as CCls adversativas podem ser antecedidas por conjunções adversativas, interjeições, pronomes ou vocativos que intensificam o valor replicativo desse fenômeno linguístico. Por meio de testes, depreendeu-se que se a conjunção "se" fosse omitida nessas construções, não haveria nenhum comprometimento do conteúdo proposicional, porém, as características pragmáticas seriam anuladas. Inclusive, tal omissão descaracterizaria essas construções no que se refere ao seu uso em situações dialógicas, em que as necessidades intersubjetivas são mais relevantes para a interação.

Ademais, o fenômeno ora analisado é definido semântica e pragmaticamente por expressar rispidez, indignação e obviedade, advinda da relação simétrica entre os interlocutores. Nesse sentido, o modo subjuntivo tampouco é pertinente, uma vez que é comumente mobilizado em situações demarcadas por uma assimetria entre os interlocutores (contextos mais formais).

As constatações observadas no nível morfossintático e semântico-pragmático mostram-se muito semelhantes ao que foi identificado no espanhol (MONTOLÍO, 1999; SCHWENTER, 1999, 2016). Porém, no espanhol, há estudos mais avançados sobre esse mesmo fenômeno, incluindo, especialmente, a prosódia como uma categoria formal de análise. Esses estudos evidenciam que a prosódia é responsável por definir a (in) dependência sintática dessas construções, além de outras características particulares, algo que se pretende corroborar em Alves (em preparação). 


\section{Agradecimentos}

Este trabalho é resultado de um projeto de Iniciação Científica financiado pela FAPESP - Fundação de Amparo à Pesquisa do Estado de São Paulo (Processo 2017/15225-9), orientado pela Profa. Dra. Flávia Bezerra de Menezes Hirata-Vale e BEPE-FAPESP - Bolsa Estágio de Pesquisa no Exterior (Processo 18/24523-6), orientado pela Profa. Dra. Renata Enghels, da Universidade de Gante, Bélgica.

\section{REFERÊNCIAS}

ALVES, C. P. Construções condicionais insubordinadas adversativas: uma análise descritiva no português do Brasil. 2020. Relatório (Iniciação Científica) - Centro de Educação e Ciências Humanas, Universidade Federal de São Carlos, São Carlos, 2020 [FAPESP, Processo n. 2017/15225-9].

BECHARA, E. Moderna gramática portuguesa. 37. ed. Rio de Janeiro: Nova Fronteira, 2009.

DECAT, M. B. N. Leite com manga morre: da hipotaxe adverbial no português em uso. 1993. Tese (Doutorado em Linguística Aplicada ao Ensino de Línguas) - Pontifícia Universidade Católica de São Paulo, São Paulo, 1993.

DECAT, M. B. N. Estruturas desgarradas em língua portuguesa. Campinas: Pontes. 2011.

D'HERTEFELT, S. Insubordination in six Germanic languages. PhD Thesis. Katholieke Universiteit Leuven. 2015.

EVANS, N. Insubordination and its uses. In: NIKOLAEVA, I. (ed.). Finiteness. Theoretical and Empirical Foundations. Oxford: Oxford University Press, 2007. p. 366-431.

EVANS, N. Insubordination and the grammaticalisation of interactive presuppositions. Paper presented at Methodologies in Determining Morphosyntactic Change, Osaka, 2009.

GRAS, P. Gramática de construcciones en interacción. Propuesta de un modelo y aplicación al análisis de estructuras independientes con marcas de subordinación en español. 2011. Tese. (Doutorado em Linguística) - Universidade de Barcelona, Barcelona, 2011. Disponível em: http://www.tesisenred.net/handle/10803/1716. Acesso em: 28 mar. 2017.

HALLIDAY, M. An introduction to Functional Grammar. London: Edward Arnold Publishers, 1985. 
HIRATA-VALE, F. B. M. O processo de insubordinação nas construções condicionais do português do Brasil. 2015. Relatório Científico Final (Bolsa de Pesquisa no Exterior FAPESP processo 13/24523-2) - Katholieke Universiteit Leuven, 2015.

HIRATA-VALE, F. B. M. A expressão da condicionalidade no português escrito do Brasil: contínuo semântico-pragmático. 2005. Tese. (Doutorado em Linguística e Língua Portuguesa) - Faculdade de Ciências e Letras, Universidade Estadual Paulista "Júlio de Mesquita Filho", Araraquara, 2005.

HIRATA-VALE, F. B. M.; OLIVEIRA, T. P.; SILVA, C. F. Construções insubordinadas no português do Brasil: completivas e condicionais em análise. ODISSÉIA, v. 2, p. 25-41, 2017.

HOPPER, P.; TRAUGOTT, E. C. Grammaticalization. Cambridge: Cambridge University Press, 2003.

LEHMANN, C. Towards a typology of clause linkage. In: HAIMAN, J.; THOMPSON, S. (ed.). Clause combining in grammar and discourse. Amsterdam: John Benjamins, 1988. p. 181-225.

MATTHIESSEN, C.; THOMPSON, S. A. The structure of discourse and subordination. In: HAIMAN, J.; THOMPSON, S. (ed.). Clause combining in grammar and discourse. Amsterdam: John Benjamins, 1988. p. 275-329.

MITHUN, M. The extension of dependency beyond the sentence. Language, v. 84, n. 1 , p. 69-119. 2008.

MONTOLÍO, E. Analisis del Discurso Oral. Universidad de Almería: Arco/Libros, 1999.

NEVES, M. H. M. Gramática de usos do português. São Paulo: Editora UNESP, 2000.

NEVES, M. H. M. A gramática. História, teoria e análise, ensino. São Paulo: Editora UNESP, 2002.

SANSIÑENA, M. S. The multiple functional load of que. An interactional approach to insubordinate complement clauses in Spanish. 2015. PhD Thesis - Katholieke Universiteit Leuven, Leuven, 2015.

SCHWENTER, S. A. Pragmatics of conditional marking: implicature, scalarity and exclusivity. New York: Garland, 1999. 
SCHWENTER, S. A. Expectations and (in)sufficiency: Spanish como-conditionals. Linguistics, v. 39, p. 733-760, 2001.

SCHWENTER, S. A. Independent si-Clauses in Spanish: Functions and Consequences for Insubordination. In: EVANS, N.; WATANABE, H. (ed.). Dynamics of Insubordination. Amsterdam: Benjamins, 2016.

STASSI-SÉ, J. Subordinação Discursiva no Português à luz da Gramática DiscursivoFuncional. 2012. Tese (Doutorado em Estudos Linguísticos) - Instituto de Biociências, Letras e Ciências Exatas, Universidade Estadual Paulista "Júlio de Mesquita Filho", São José do Rio Preto, 2012.

VAN LINDEN, A.; VAN DE VELDE, F. (Semi-)autonomous subordination in Dutch: Structures and semantic-pragmatic values. Journal of Pragmatics. 2014. Disponível em: http://dx.doi.org/10.1016/j.pragma.2013.08.022. Acesso em: 28 mar. 2017.

VERSTRAETE, J. C. Rethinking the coordinate-subordinate dichotomy: Interpersonal grammar and the analysis of adverbial clauses in English (Topics in English Linguistics 55). Berlin: Mouton de Gruyter, 2007.

VERSTRAETE, J. C. Two types of coordination in clause combining. Lingua, n. 115, p. 611-626, 2005.

VERSTRAETE, J.; D'HERTEFELT, S.; VAN LINDEN, A. A typology of complement insubordination in Dutch. Studies in Language, v. 1, n. 36, p. 123-153, 2012. 